\title{
Stability and function of the signal peptide of the pCloDF13-derived bacteriocin release protein
}

\author{
Fimme J. van der Wal, Quido A. Valent, \\ Corinne M. ten Hagen-Jongman, Frits K. de Graaf, \\ Bauke Oudega and Joen Luirink \\ Author for correspondence: Fimme J. van der Wal. Tel: +3120 5485715. Fax: + 31206429202.
e-mail: vdwal@bio.vu.nl
}

Department of Microbiology, Institute of Molecular Biological Sciences, Biocentrum Amsterdam, de Boelelaan 1087, 1081 HV Amsterdam, The Netherlands

\begin{abstract}
The pCloDF13-derived bacteriocin release protein (BRP) is synthesized as a prelipoprotein with a signal peptide which remains stable after processing. This signal peptide accumulates in the cytoplasmic membrane and is, together with the mature BRP, required for efficient release of cloacin DF13. We investigated the structural requirements for stability of the BRP signal peptide by constructing hybrid signal peptides consisting of parts of the BRP and Lpp signal peptides. Signal peptide stability was investigated by pulse-labelling and pulse-chase experiments. To study the functioning of the BRP signal peptide, the hybrid constructs were tested for their ability to promote BRPmediated cloacin DF13-release and their ability to affect the viability of the host cells. The results obtained suggest that the $\mathbf{N}$-terminal part of the BRP signal peptide together with the C-terminal alanine residue are important for stability. When expressed as a separate entity, all mutant signal peptides that contain a part of the BRP signal peptide are capable of affecting cell viability. The results indicated a possible correlation between stability of the BRP signal peptide and cloacin DF13-release.
\end{abstract}

Keywords: bacteriocin release protein, cloacin DF13, signal peptide stability, processing, Escherichia coli

\section{INTRODUCTION}

Bacteriocin release proteins (BRPs, also called lysis proteins or kil proteins) are involved in the semi-specific transfer of colicins and cloacin DF13 across the cell envelope of Escherichia coli. Expression of BRPs also results in a decline in culture turbidity (quasi-lysis or 'lysis'), inhibition of colony formation on agar plates (lethality) and leakage of periplasmic proteins by host cells (Pugsley, 1984; De Graaf \& Oudega, 1986).

The pCloDF13-derived BRP is synthesized as a precursor lipoprotein of 49 amino acid residues. The preBRP is slowly processed by the lipoprotein-specific signal peptidase II (SPaseII), rendering a lipid-modified mature $\mathrm{BRP}$ which is located primarily in the outer membrane of

Abbreviations: BRP, bacteriocin release protein; SPasell, signal peptidase II.
E. coli (Oudega et al., 1984; Van der Wal et al., 1992). By constructing hybrid BRP-derived proteins containing sorting sequences for proteins located in the cytoplasmic membrane, it was shown that the mature BRP itself contains structural information for its outer-membrane localization (Gennity et al., 1992). The signal peptides of most BRPs are unusual in that they are not proteolytically degraded after processing of the preBRP (Cavard $e t$ al., 1987; Pugsley \& Cole, 1987; Luirink et al., 1989). The stable signal peptides accumulate in the cytoplasmic membrane (Howard et al., 1991; Van der Wal et al., 1992).

The role of the pCloDF13-derived stable BRP signal peptide has been investigated by genetically exchanging the stable BRP signal peptide for the unstable Lpp signal peptide. The resulting hybrid BRP, correctly targeted by the Lpp signal peptide (Gennity et al., 1992; Van der Wal et al., 1992), did not function in the release of cloacin DF13, but expression did result in quasi-lysis, lethality and leakage of periplasmic proteins (Luirink et al., 1991). 
The BRP signal peptide expressed alone was not able to provoke the release of cloacin DF13, but did cause quasilysis and lethality (Van der Wal et al., 1992).

In this study we investigated the structural requirements for BRP signal peptide stability and the possible correlation between signal peptide stability and release of cloacin DF13. Hybrid signal peptides consisting of parts of the unstable Lpp signal peptide and parts of the stable BRP signal peptide, as well as mutant BRP signal peptides, were analysed with respect to stability and ability to function in cloacin DF13-release, quasi-lysis and lethality.

\section{METHODS}

Bacterial strains, media and plasmids. E. coli MV1190 $\Delta($ lac-pro $A B)$ thi supE $\Delta(\operatorname{srl}-\operatorname{rec} A) 306:: \operatorname{Tn} 10\left(\right.$ tet $\left.^{r}\right)\left[\mathrm{F}^{\prime}: \operatorname{traD} 36\right.$ pro $A B$ lacl ${ }^{\mathrm{a}}$ lacZ $\Delta \mathrm{M} 15$ ] (Messing, 1983) and E. coli CJ236 dut-1 ung-1 thi-1 relA1; pCJ105 $\left(\mathrm{Cm}^{\mathrm{r}}\right)$ (Joyce \& Grindley, 1984; Kunkel et al., 1987) were used as host strains for the construction of mutant genes and DNA sequencing. The sup strain E. coli FTP4170 $\Delta(\operatorname{ton} \mathrm{B} \operatorname{trp} A E) \operatorname{argE}(\mathrm{Am}) \operatorname{gly} V 55$ was used for studying the expression of BRP derivatives (Luirink et al., 1989).

YT medium (Miller, 1972) was used for culturing E. coli strains MV1190 and CJ236, and also for routine culturing of E. coli FTP4170. YT medium supplemented with $20 \mathrm{mM} \mathrm{MgCl}_{2}$, to reduce BRP induced quasi-lysis, was used in cloacin DF13 release experiments (Luirink et al., 1986). M9 minimal medium (Miller, 1972), supplemented with $20 \mathrm{mM} \mathrm{MgCl}$, and $0.5 \%$ sodium lactate, was used for the labelling of cells with $\left[{ }^{3} \mathrm{H}\right]$ amino acids. Proteose peptone beef extract (Tokunaga \& Wu, 1984) was used for the labelling of cells with $\left.{ }^{3} \mathrm{H}\right]$ palmitic acid. Ampicillin $\left(100 \mu \mathrm{g} \mathrm{ml}^{-1}\right)$ and tetracycline $\left(12.5 \mu \mathrm{g} \mathrm{m}^{-1}\right)$ were added to the culture media when required. IPTG was used to induce the synthesis of BRP and BRP-related mutant proteins. Mitomycin $C$ was used at $500 \mathrm{ng} \mathrm{ml}^{-1}$ to induce cloacin DF13 synthesis.

pJL22 ( $S p h \mathrm{I})$ encoding the wild-type BRP, pJL $32-\mathrm{T}_{1}$ encoding a hybrid Lpp-BRP, pJL38 encoding the stable BRP signal peptide alone and pJL40 encoding the unstable Lpp signal peptide alone were described previously (Luirink et al., 1991; Van der Wal et al., 1992) and were used either for the construction of mutant BRP genes or as a control in lysis experiments. The expression vector pINIIIA1 (Masui et al., 1984) was used for the expression of all mutant BRP constructs. pJL25, a pACYC184-derivative compatible with the constructed pINIIIA1-derivatives, encodes cloacin DF13 under control of the mitomycin C-inducible SOS promoter (Luirink et al., 1988), and was used to study the specific cloacin release in complementation experiments with various BRP constructs.

Recombinant DNA techniques. Plasmid DNA and M13 doublestranded DNA were isolated as described by Birnboim \& Doly (1979). Transformation of cells was carried out as described by Mandel \& Higa (1970). Site-directed mutagenesis was carried out as described by Kunkel et al. (1987), using the Muta-gene M13 in vitro Mutagenesis Kit (BioRad). Mutants were identified using the dideoxy-termination method of Sanger et al. (1977) with the Taq Dye Primer Cycle Sequencing Kit and the 373A Automated DNA Sequencer of Applied Biosystems. To confirm that only desired mutations had taken place, the complete DNA sequence of subcloned mutated gene fragments was determined. All other basic recombinant DNA techniques were carried out using methods described by Sambrook et al. (1989).
Construction of mutant BRP genes. To enable the exchange of signal peptide coding regions, a NarI site was introduced in the middle of the BRP signal peptide gene. For this construction, an $X b a \mathrm{I}-E c o$ RI fragment of $\mathrm{pJL22}(S p b \mathrm{I})$ encompassing the coding region of the complete preBRP, was cloned into M13mp19 using polylinker restriction sites. A Narl site in the coding region of the BRP signal peptide was created by in vitro mutagenesis using the oligonucleotide $5^{\prime}$ CTA T'T'T T'TC TTG GCG CCT 'TG 3' (aitered nucleotides are underlined). As a consequence, two triplets encoding amino acid residues 10 and 11 were changed from TTT ATA (Phe-Ile) to GGC GCC (GlyAla), resulting in $\mathrm{M} 13 \mathrm{mp} 19 \mathrm{cl} 21$.

Likewise, a NarI site was introduced in the middle of the Lpp signal peptide gene. For this mutagenesis, a M13mp18 construct containing the $\mathrm{pJL} 32-\mathrm{T}_{1}$-derived $1.2 \mathrm{~kb}$ SalI fragment encoding the hybrid LpP-BRP was used. The oligonucleotide $5^{\prime} \mathrm{CAG}$ GAT TAC GGC GCC CAG $3^{\prime}$ was used to introduce the NarI site, thereby changing the ninth triplet from GCC (Ala) to GCG (Ala). This construct was named M13mp18cl24.

For the construction of a mutant preBRP with a hybrid Lpp-BRP signal peptide, a $0.4 \mathrm{~kb}$ NarI fragment of M13mp19cl21 was ligated into the $5.8 \mathrm{~kb}$ NarI fragment of M13mp18cl24, resulting in M13mp18(21S24L) encoding the preBRP 10Lpp10BR P-BRP. The hybrid gene was cloned into pINIIIA1, resulting in pJL42 (Table 1).

For the construction of an amber mutant of pJL42 encoding only the hybrid Lpp-BRP signal peptide, a $0.4 \mathrm{~kb}$ HindIII fragment from $\mathrm{pJL} 42$ was ligated into M13mp18. The resulting construct was used for the introduction of an amber mutation at the first triplet of the gene encoding the mature BRP with the oligonucleotide 5' GT'T TGC CTG CTA TGC GAC CAG 3'. The mutated signal peptide was cloned into pINIIIA1 using polylinker restriction sites. The resulting plasmid encoding the 10Lpp10BRP signal peptide was designated pJL45 (Table 1).

To construct a mutant preBRP with a hybrid BRP-Lpp signal peptide, a small $(1 \cdot 2 \mathrm{~kb})$ NarI fragment of M13mp18cl24 was ligated into the M13mp19cl21-derived large $(6.6 \mathrm{~kb})$ NarI fragment which resulted in M13mp19(21L24S), encoding the hybrid 9BRP11LppAla-BRP precursor. This hybrid gene was cloned into pINIIIA1, resulting in pJL44 (Table 1).

For the construction of an amber mutant encoding only the hybrid BRP-Lpp signal peptide, M13mp19(21L24S) was used to introduce an amber mutation at the first triplet of the gene encoding the mature BRP with the oligonucleotide $5^{\prime}$ CTG CTG GCA GGT TGC TAG GCA AAC TA 3' thereby reverting the last alanine residue of the signal peptide into a glycine residue. The mutated fragment encoding the hybrid 9BR P12L $p p$ signal peptide was cloned into pINIIIA1, resulting in pJL46 (Table 1).

For the construction of a mutant preBRP with a BRP signal peptide mutated in the hydrophobic core region, the complete hybrid BRP gene from M13mp19cl21, encoding 9BRPGly Ala10BRP-BRP was cloned into pINIIIA1, resulting in PJL47 (Table 1).

For the construction of an amber mutant encoding only the BRP signal peptide mutated in the hydrophobic core, a $0.4 \mathrm{~kb}$ HindIII-EcoRI fragment of M13mp19cl21 was cloned into M13mp18. An amber mutation was introduced at the first triplet of the gene encoding the mature BRP with the oligonucleotide 5' GT'T 'TGC CTG CTA TGC GAC CAG 3'. The fragment was ligated into pINIIIA 1 , resulting in pJL49 encoding the mutated 9BRPGly Ala10BRP signal peptide (Table 1).

Unintentionally, the mutagenesis procedure used for the con- 


\section{Table 1. List of BRP derivatives used}

The names of signal peptides used throughout the text are printed in italics, whereas the mature BRP is printed in bold type. The corresponding amino acid sequences are listed and aligned with respect to the SPaseII cleavage site. Lpp signal peptide-derived residues are underlined. For comparison, the complete amino acid sequence of the wild-type (wt) Lpp signal peptide is presented (Nakamura \& Inouye, 1979). The primary sequence of mBRP is CQANYIRDVQGGTVAPSSSSELTGIAVQ (De Graaf \& Oudega, 1986) and is referred to as CQA .... in the table.

\begin{tabular}{|c|c|c|}
\hline Plasmid & Gene product & Amino acid sequence \\
\hline pJL22(SphI) & $w t B R P-\mathbf{B R P}$ & MKKAKAIFLFILIVSGFLLVA $\downarrow C Q A \ldots$ \\
\hline pJL32-T $T_{1}$ & $m u t L p p-\mathbf{B R P}$ & MKATKLVLGAVILGSTLLAA $\downarrow C Q A \ldots$ \\
\hline plL42 & 10Lppp10BRP-BRP & MKATKLVLGALIVSGFLLVA $\downarrow C Q A \ldots$ \\
\hline pJL45 & 10Lpp10BRP & MKATKLVLGALIVSGFLLVA \\
\hline pJL44 & 9BRP11LppAla-BRP & MKKAKAIFLGAVILGSTLLAA $\downarrow C Q A \ldots$ \\
\hline plL46 & 9BRP12Lpp & MKKAKAIFLGAVILGSTLLAG \\
\hline p $\int L 47$ & 9BR PGly Ala10BRP-BRP & MKKAKAIFLGALIVSGFLLVA $\downarrow C Q A \ldots$ \\
\hline p) 1549 & 9BRPGly Ala10BRP & MKKAKAIFLGA $L I V S G F L L V A$ \\
\hline pjL38 & $w t B R P$ & MKKAKAIFLFILIVSGFLLVA \\
\hline plL43 & 9BRPGly & MKKAKAIFLG \\
\hline & wt $L p p$ & MKATKLVLGAVILGSTLLAG \\
\hline
\end{tabular}

struction of $\mathrm{M} 13 \mathrm{mp} 19 \mathrm{cl} 21$ also resulted in an amber mutation in the signal peptide coding region. This resulting plasmid encodes a peptide of 10 residues containing the nine $\mathrm{N}$-terminal residues of the BRP signal peptide and, at the last position, a glycine residue. This peptide is referred to as 9BRPGly. A DNA fragment encoding this peptide was cloned into pINIIIA1, resulting in pJL43 (Table 1 ).

Analysis of gene products by discontinuous tricine SDSPAGE. Gene products were analysed using highly cross-linked $16.5 \%(\mathrm{w} / \mathrm{v})$ polyacrylamide in tricine SDS-PAGE, as described by Schägger \& Von Jagow (1987).

Radiolabelling of proteins. For labelling experiments, exponentially growing cells $\left(2 \times 10^{8}\right.$ cells $\left.\mathrm{ml}^{-1}\right)$ were induced with $1 \mathrm{mM}$ IPTG. When required, globomycin, an inhibitor of SPaseII (Dev et al., 1985), (a kind gift of M. Inukai, Sankyo Co., Tokyo, Japan) dissolved in dimethylsulfoxide $\left(5 \mathrm{mg} \mathrm{ml}^{-1}\right)$ was added to a final concentration of $100 \mu \mathrm{g} \mathrm{ml}^{-1}, 5 \mathrm{~min}$ prior to induction with IPTG. After $10 \mathrm{~min}$ of induction, a mixture of $\left[{ }^{3} \mathrm{H}\right]$ amino acids $\left(16 \mathrm{Ci} \mathrm{mmol}^{-1} ; \quad 0.59 \mathrm{TBq} \mathrm{mmol}^{-1}\right)$ or $\left.{ }^{3} \mathrm{H}\right]$ palmitic acid $\left(53 \mathrm{Ci} \mathrm{mmol}^{-1} ; 1.96 \mathrm{TBq} \mathrm{mmol}^{-1}\right.$ ) (Amersham) was added to a final concentration of 25 and $50 \mu \mathrm{Ci} \mathrm{m}^{-1}$, respectively. Before labelling with $\left[{ }^{3} \mathrm{H}\right]$ amino acids, cells were collected by centrifugation and resuspended in 0.5 vols minimal medium. After $30 \mathrm{~min}$ of labelling, cells incubated with $\left[{ }^{3} \mathrm{H}\right]$ amino acids were collected by centrifugation, washed with PBS and dissolved in sample buffer. Labelling of fatty-acylated proteins with $\left[{ }^{3} \mathrm{H}\right]$ palmitic acid was terminated by adding trichloroacetic acid to a final concentration of $10 \%(\mathrm{w} / \mathrm{v})$. For pulse-chase experiments, cells were labelled for $10 \mathrm{~min}$ with a mixture of $\left[{ }^{3} \mathrm{H}\right]$ amino acids (final concentration $20 \mu \mathrm{Ci} \mathrm{m} l^{-1}$ ) and chased with $0.2 \%$ Casamino acids, as described previously (Luirink et al., 1989, 1991). Subsequently, the cells were collected by centrifugation, washed twice with methanol and dissolved in sample buffer. The samples were analysed by tricine SDS-PAGE and fluorography.

Determination of quasi-lysis, lethality and release of cloacin DF13, MDH and $\boldsymbol{\beta}$-lactamase. Quasi-lysis was determined by measuring the optical density at $660 \mathrm{~nm}$ of induced cell cultures, as described previously (Luirink et al., 1989). Lethality caused by expression of BRP-derived constructs was determined as described previously (Luirink et al., 1989). The amount of cloacin DF13 released into the culture medium or remaining in the cells was determined in triplicate with an ELISA as described previously (Luirink et al., 1987). Double transformants of E. coli FTP4170 harbouring PJL25 and one of the various PINIIIA1derivatives were employed. The double transformants were moderately induced for expression of BRP or BRP-derived constructs with $20 \mu \mathrm{M}$ IPTG and fully induced for synthesis of cloacin DF13 with $500 \mathrm{ng}$ mitomycin $\mathrm{C} \mathrm{ml}^{-1}$. The release of $\mathrm{MDH}$ and $\beta$-lactamase was measured as described by Bergmeyer \& Bernt (1983) and Luirink et al. (1988).

\section{RESULTS}

\section{Construction of mutant BRPs}

In contrast to the Lpp signal peptide (Hussain et al., 1982), the BRP signal peptide remains stable after processing of the preBRP (Luirink et al., 1989). Furthermore, a BRP targeted by the unstable Lpp signal peptide does not function in the release of cloacin DF13 (Luirink et al., 1991), which indicated that the accumulated stable signal peptide is involved in cloacin DF13-release. Therefore, the origin of signal peptide stability and functioning of the signal peptide with respect to cloacin DF13-release, quasi-lysis and lethality was further studied by constructing hybrid BRP-derived signal peptides.

Three different mutant signal peptides coupled to the mature BRP were constructed; a hybrid LPP-BRP signal peptide, a hybrid BRP-Lpp signal peptide, and a BRP signal peptide mutated in the hydrophobic core region by substitution of two large hydrophobic residues for two small, less hydrophobic residues which are present at the same position in the Lpp signal peptide. The latter mutant was constructed in an attempt to destabilize the BRP signal peptide since it is known that this peptide contains more hydrophobic and bulky amino acid residues than the 
(a)

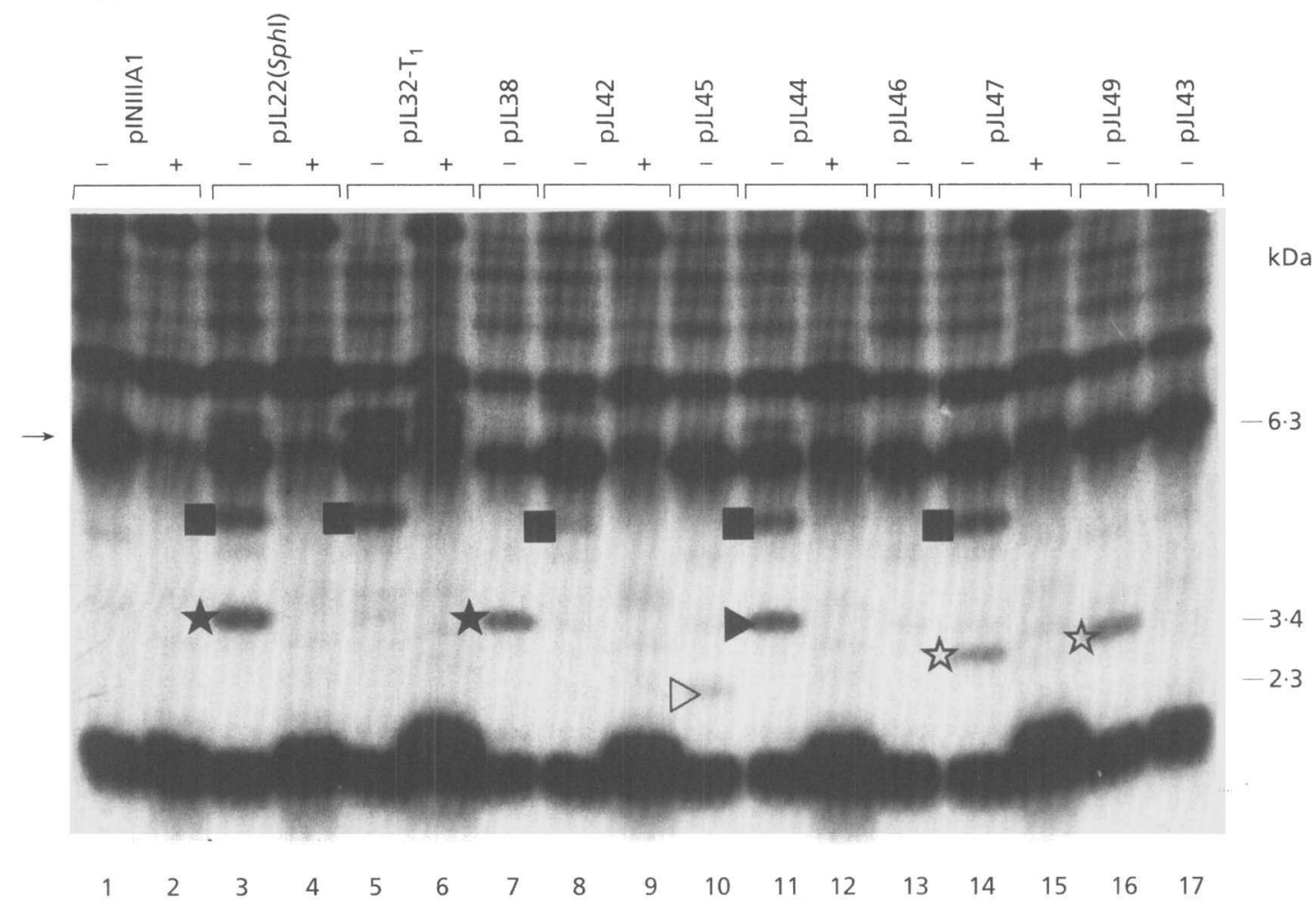

(b)

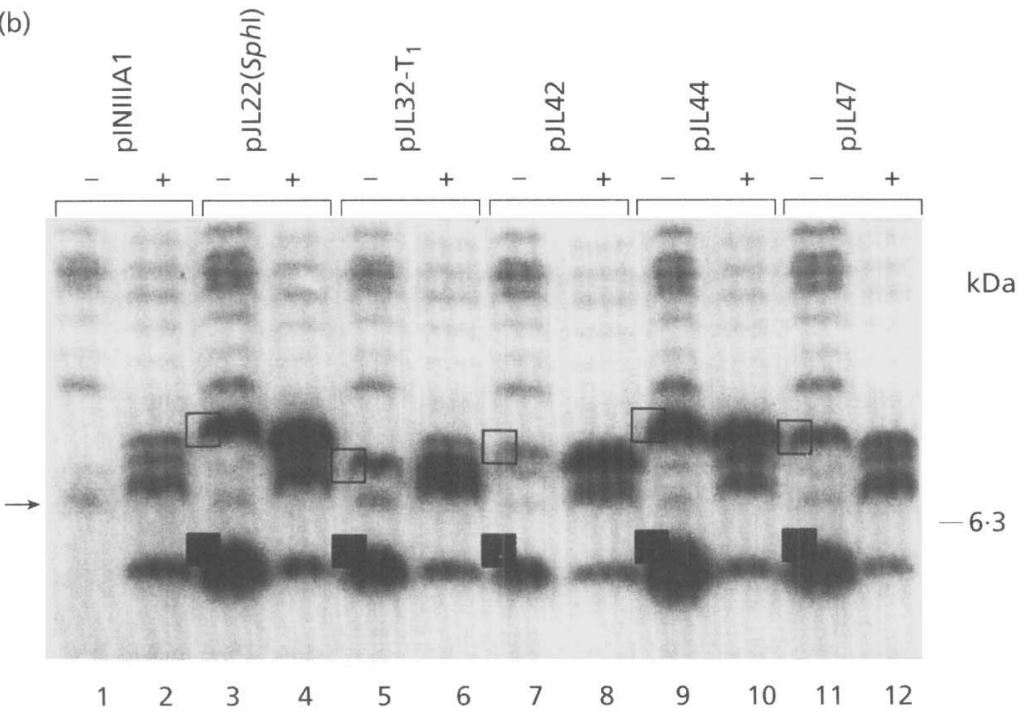

(e)

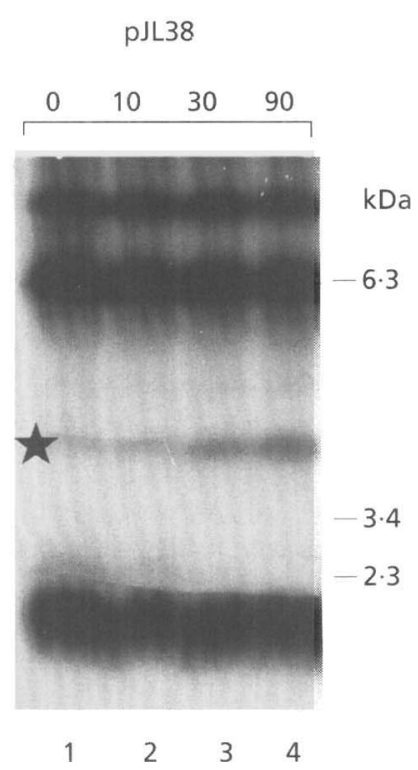

Fig. 1 (a), (b), (e). For legend see facing page.

unstable Lpp signal peptide (Klein et al., 1988). Furthermore, to study the effects of expression of the mutant BRP signal peptides alone, amber mutants were made by introducing a stop codon at the first triplet of the mature BRP coding region. In addition, a truncated BRP signal peptide was created containing only nine amino acid 
(c)

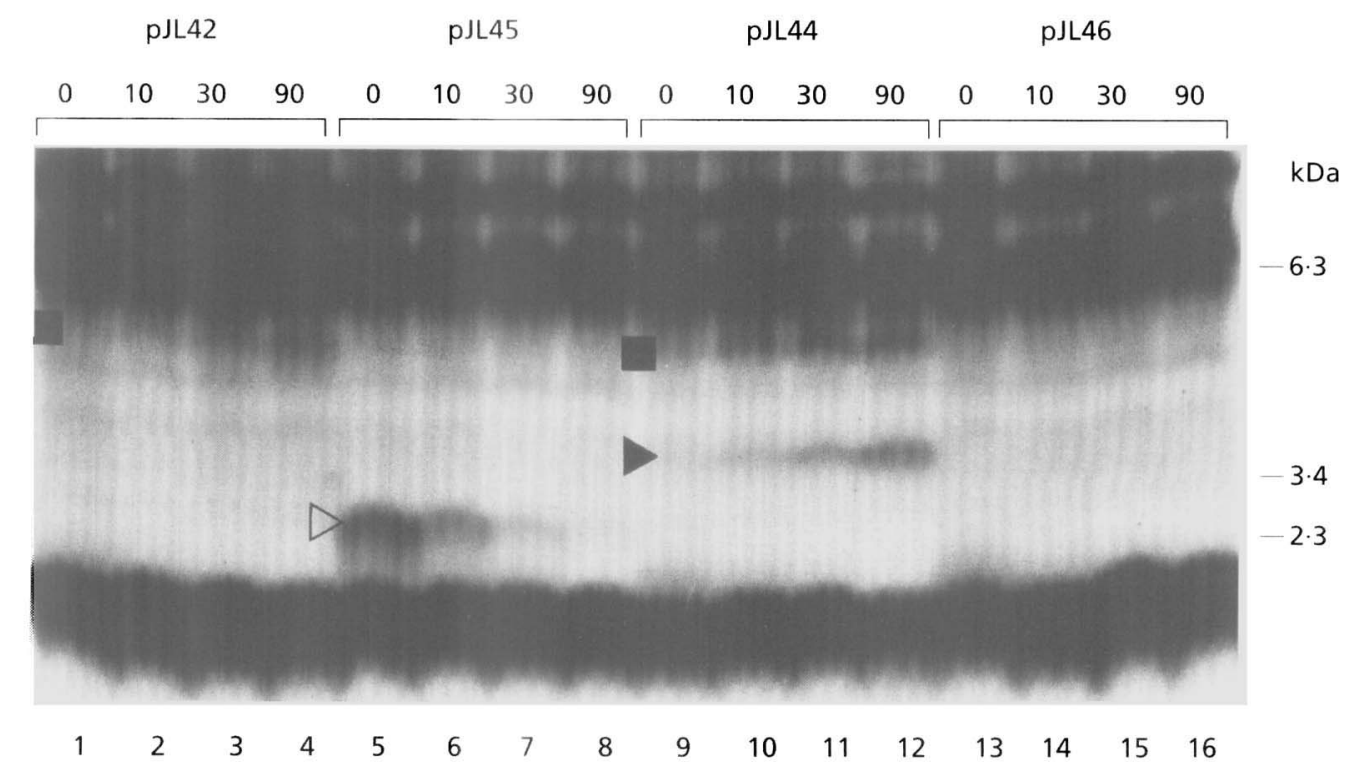

(d)

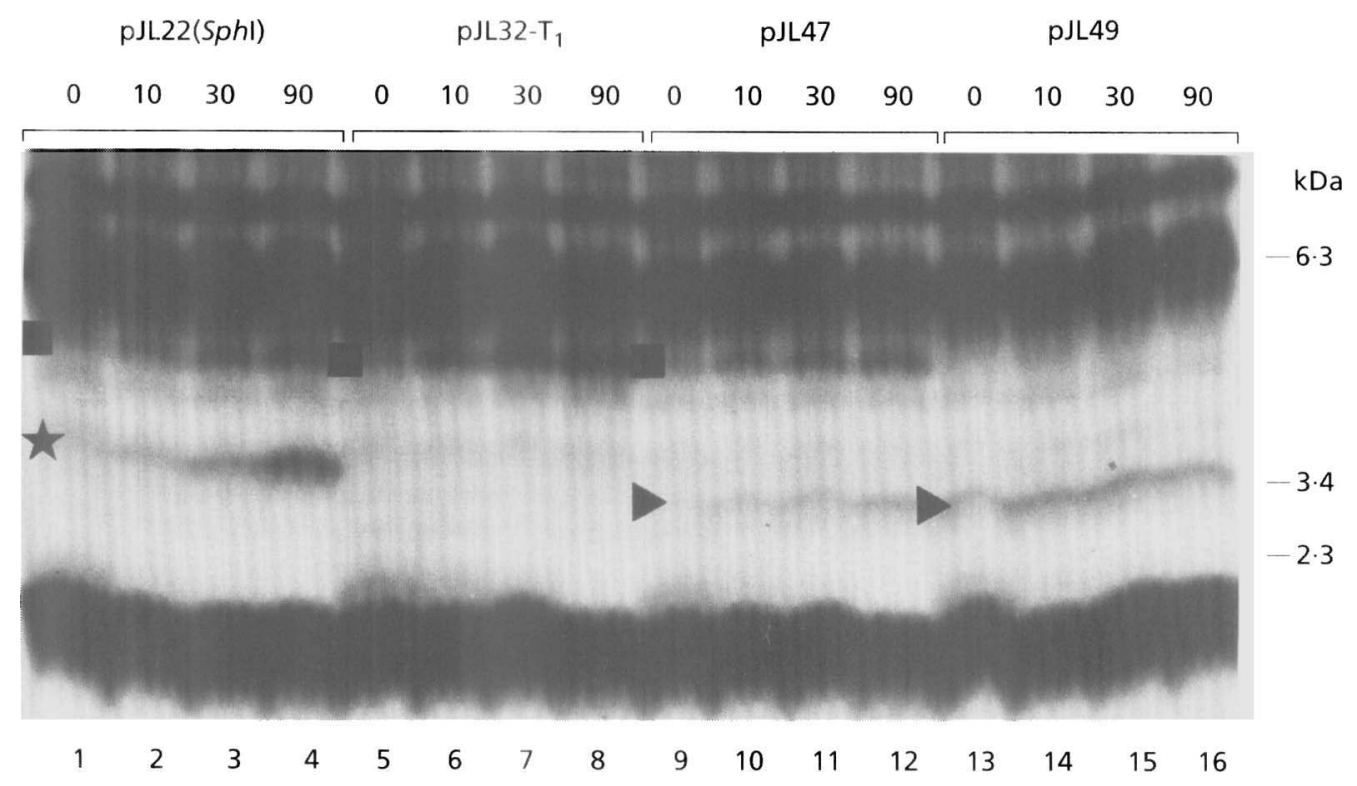

Fig. 1. Identification of plasmid-encoded gene products by tricine SDS-PAGE and fluorography. Cells of E. coli FTP4170 harbouring either pINIIIA1 or one of the various pJL plasmids (as indicated at the top) were labelled with [ $\left.{ }^{3} \mathrm{H}\right]$ amino acids (a) or $\left[{ }^{3} \mathrm{H}\right]$ palmitic acid (b) and analysed as described in the text. The absence or presence of globomycin during labelling is indicated above the figure by - or + , respectively. By pulse-chase labelling with $\left[{ }^{3} \mathrm{H}\right]$ amino acids, precursor processing and signal peptide stability were investigated $(c, d, e)$. After various time periods of chase (indicated in min above the figure) samples were taken and analysed as described in the text. The position of marker polypeptides ( $k D a)$ is indicated. Symbols: $\square$, lipid-modified preBRPs; $\square$, mBRP; $\star$, stable BRP signal peptide; $D$, hybrid 10Lpp10BRP signal peptide and possible proteolytic fragments; $\rightarrow$, hybrid 9BRP11LppAla signal peptide; $\tau_{3}$, hybrid 9BRPGlyAla10BRP signal peptide; $\rightarrow$, mature Lpp.

residues of the wild-type BRP signal peptide plus a $\mathrm{C}$ terminal glycine residue. All mutated genes were subcloned in the expression vector pINIIIA1 under control of the IPTG-inducible tandem lpp-lac promoter/ operator. The primary sequences of the encoded peptides are listed in Table 1. 


\section{Expression of BRP-derivatives}

The expression of mutant BRP-derivatives was studied in E. coli FTP4170 by labelling with $\left[{ }^{3} \mathrm{H}\right]$ amino acids (Fig. 1a). Polypeptide bands representing the stable wild-type BRP signal peptide, encoded by pJL22(SphI) and pJL38 (Fig. 1a, lanes 3 and 7), and the mature lipid-modified BRP (mBRP), encoded by pJL22( $S p b \mathrm{I})$ and pJL32- $\mathrm{T}_{1}$ (Fig. 1a, lanes 3 and 5), have been identified previously (Luirink et al., 1991). Cells harbouring pJL42, pJL44 or pJL47, encoding hybrid preBRPs, all expressed the mBRP (Fig. 1a, lanes 8,11 and 14). The band representing the pJL42-encoded mBRP (Fig. 1a, lane 8) was much less intense than the pJL22(SphI)-encoded mBRP (Fig. 1a, lane 3 ) indicating that either its expression or its rate of processing is affected.

In addition to the $\mathrm{mBRP}$ expressed by cells harbouring pJL44 (9BRP11LppAla-BRP), a polypeptide band comigrating with the wild-type BRP signal peptide was detected (Fig. 1a, lane 11). This band probably represents the pJL44-encoded 9BRP11LppAla signal peptide (predicted $\left.M_{\mathrm{r}} 2117\right)$ which is apparently stable.

Analysis of cells harbouring pJL47 (9BRPGly Ala10BRPBRP) showed the presence of a polypeptide band (Fig. 1a, lane 14) which migrated slightly faster than the wild-type BRP signal peptide. This band probably represents the pJL47-encoded mutant signal peptide (predicted $M_{\mathrm{r}}$ 2191) which is apparently less stable than the wildtype BRP signal peptide, as can be deduced from its lower intensity. Alternatively, it could be a proteolytic fragment of the mutant signal peptide.

In cells harbouring pJL42 (10Lpp10BRP-BRP), the hybrid signal peptide was not detected (Fig. 1a, lane 8; predicted $M_{\mathrm{r}} 2045$ ) indicating that it is not stable. It must be noted, however, that the pJL42-encoded mutant BRP is expressed (or processed) to a lesser extent than the wildtype BRP (see above).

To study the expression of the mutant signal peptides alone (not coupled to the $\mathrm{mBRP}$ ), similar labelling experiments were carried out with E. coli FTP4170 harbouring either pJL45, pJL46, or pJL49 (see Table 1). As described in Methods, these plasmids contain an amber mutation immediately after the signal peptide coding region, and expression in the suppressor-negative E. coli strain FTP4170 should result in the synthesis of the signal peptides only. In addition, the fortuitously obtained pJL43, encoding a peptide of 10 residues, was tested. Cells expressing the stable wild-type BRP signal peptide without the mBRP (pJL38; Van der Wal et al., 1992) were used as a control.

In cells harbouring pJL45 (10LPp10BRP; predicted $M_{\mathrm{r}}$ 2045) a weak polypeptide band of lower intensity, and migrating slightly faster than the wild-type BRP signal peptide, was detected (Fig. 1a, lane 10). This band probably represents the pJL45-encoded mutant signal peptide which is apparently less stable than the wild-type $\mathrm{BRP}$ signal peptide. Alternatively, it could be a proteolytic fragment of the mutant signal peptide.
The pJL46-encoded 9BRP12Lpp signal peptide (Fig. 1a, lane 13; predicted $M_{\mathrm{r}}$ 2013) was not detected, in contrast to the comparable cleaved-off pJL44-encoded hybrid signal peptide, indicating that it is unstable (see Discussion).

Analysis of cells expressing the mutant pJL49-encoded 9BRPGlyAla10BRP signal peptide (predicted $M_{\mathrm{r}} 2191$ ) revealed the presence of a polypeptide (Fig. 1a, lane 16) of which the intensity was almost as high as that of the wildtype BRP signal peptide. The peptide comigrated with the signal peptide expressed by pJL47-harbouring cells. This band probably represents the pJL49-encoded mutant signal peptide itself, or its proteolytic breakdown product, as pointed out for the pJL47-encoded cleaved-off mutant signal peptide.

Finally, the expression of the pJL43-encoded truncated signal peptide (9BRPGly; predicted $M_{\mathrm{r}}$ 1107) was studied (Fig. 1a, lane 17). This peptide could not be detected, possibly because of its small size.

\section{Lipid-modification and processing by SPasell}

By labelling cells with $\left[{ }^{3} \mathrm{H}\right]$ amino acids and $\left[{ }^{3} \mathrm{H}\right]$ palmitic acid in the absence and presence of globomycin, an inhibitor of the prolipoprotein signal peptidase SPaseII (Dev et al., 1985), the lipid-modification and processing of all mutant preBRPs was investigated (Fig. 1a and b).

The mBRPs expressed by cells harbouring pJL22(Sphl), pJL32-T 1 , pJL42, pJL44 or pJL47 were detected after labelling with $\left[{ }^{3} \mathrm{H}\right]$ palmitic acid (Fig. 1b, lanes $3,5,7,9$ and 11), indicating that these mBRPs are all lipidmodified. Upon treatment with globomycin, the lipidmodified preBRPs accumulated at the expense of the mBRPs (Fig. 1a, lanes 4, 6, 9, 12 and 15; Fig. 1b, lanes 4, $6,8,10$ and 12 ), indicating that all preBRPs are processed by SPaseII which can only cleave lipid-modified precursors (Wu \& Tokunaga, 1986). Again, the pJL42encoded preBRP and $\mathrm{mBRP}$ appeared less intense, which is probably caused by the lower expression of this construct (see Fig. 1b, lane 7).

\section{Signal peptide stability and rates of processing}

The stability of the signal peptides and the rates of processing of the various preBRPs were investigated by pulse-chase labelling with $\left[{ }^{3} \mathrm{H}\right]$ amino acids (Fig. $1 \mathrm{c}, \mathrm{d}$ and e).

As can be seen from the increase in intensity of the mBRP encoded by pJL44, the rate of processing of 9BRP11LppAla-BRP (Fig. 1c, lanes 9-12) is comparable to that of the wild-type preBRP (Fig. 1d, lanes 1-4). The intensity of the pJL44-encoded cleaved-off 9BRP11LppAla signal peptide increased throughout the chase period comparable to the cleaved-off wild-type signal peptide, indicating that these signal peptides are of similar stability.

The pJL46-encoded 9BRP12L $p p$ signal peptide expressed 
Table 2. Effects of expression of BRP-derivatives on cloacin DF13-release, quasi-lysis and lethality

\begin{tabular}{|lccc|}
\hline Plasmid & $\begin{array}{c}\text { Percentage } \\
\text { BRP-mediated } \\
\text { cloacin release* }\end{array}$ & $\begin{array}{c}\text { Quasi-lysis } \dagger \\
\text { Lethality } \ddagger \\
\text { (mM } \\
\text { IPTG) }\end{array}$ \\
\hline pJL22(SphI) & 30 & ND & ND \\
pJL32-T & 0 & ND & ND \\
PJL42 & 20 & ND & ND \\
pJL44 & 33 & ND & ND \\
pJL47 & 23 & ND & ND \\
pJL45 & ND & ++ & $0 \cdot 0625$ \\
PJL46 & ND & + & $0 \cdot 125$ \\
PJL49 & ND & + & $0 \cdot 125$ \\
PJL43 & ND & + & $0 \cdot 250$ \\
PJL38 & ND & +++ & $0 \cdot 125$ \\
pJL40 & ND & - & $>4$ \\
\hline
\end{tabular}

ND, Not determined

* Double transformants of E. coli FTP4170, harbouring pJL25 encoding cloacin DF13 and one of the various plasmids encoding a preBRP, were induced for the synthesis of cloacin DF13 and BRP. After $5 \mathrm{~h}$, samples were taken and the amount of cloacin DF13 released was determined using an ELISA as described previously (Luirink et al., 1987).

†Quasi-lysis was determined for E. coli FTP4170 cells expressing the mutant BRP-derivatives, by measuring the optical density at $660 \mathrm{~nm}$ of induced cell cultures up to $5 \mathrm{~h}$ after induction.

$\ddagger$ Lethality was determined as described previously (Luirink et al., 1989) by spotting stationary-phase cultures on broth agar plates containing different concentrations of IPTG. The data given are the IPTG concentrations at which colony forming was inhibited.

alone, however, was not detected (Fig. 1c, lanes 13-16), indicating that it is unstable.

The rate of processing of the pJL47-encoded 9BR PGly Ala10BR P-BRP (Fig. 1d, lanes 9-12) was comparable to that of the wild-type preBRP, as could be deduced from the increase of $\mathrm{mBR} P$ during the chase. The intensity of the pJL47-encoded cleaved-off mutant signal peptide, however, remained low throughout the chase period. This peptide migrated slightly faster than the wild-type BRP signal peptide, as observed above (see Fig. $1 \mathrm{a}$, lane 14). These observations indicated that the 9BRPGlyAla10BRP signal peptide (or its proteolytic fragment) is not as stable as the wild-type BRP signal peptide, but more stable than the Lpp signal peptide.

The comparable signal peptide expressed alone (pJL49) did not accumulate to the same extent as the wild-type BRP signal peptide expressed alone (Fig. 1d, lanes 13-16; Fig. 1e, lanes 1-4), indicating again that the 9BRPGly Ala10BR P signal peptide is less stable than the wild-type BRP signal peptide.

The kinetics of the processing of the pJL42-encoded 10Lpp10BRP-BRP (Fig. 1c, lanes 1-4) seem roughly similar to these of the wild-type preBRP encoded by
pJL22(SpbI) (Fig. 1d, lanes 1-4). As observed in the pulse labelling with $\left[{ }^{3} \mathrm{H}\right]$ amino acids and $\left[{ }^{3} \mathrm{H}\right]$ palmitic acid (Fig. 1a, lane 8 ; Fig. 1b, lane 7 ), the extent to which the pJL42encoded $\mathrm{mBRP}$ accumulated is relatively low, indicative of impaired expression. The cleaved-off 10Lpp10BRP signal peptide was not detected, indicating that this hybrid signal peptide is not stable.

In cells harbouring pJL45 encoding the 10Lpp10BRP signal peptide alone (predicted $M_{\mathrm{r}} 2045$ ), a fast migrating peptide could be detected. This band, which decreased in intensity during the chase period (Fig. 1c, lanes 5-8), probably represents the unstable hybrid 10Lpp10BRP signal peptide or its proteolytic fragment.

\section{Release of cloacin DF13}

To study the stability of the mutant BRP signal peptides and their functioning in the release of cloacin DF13, cells harbouring pJL42, pJL44 or pJL47 were transformed with pJL25, encoding cloacin DF13 under control of the mitomycin $\mathrm{C}$-inducible SOS promoter. The double transformants were moderately induced for expression of the BRP derivatives, and fully induced for synthesis of the pJL25-encoded cloacin DF13. Under conditions similar to the conditions used in this study, E. coli cells expressing the mBRP, targeted by the stable wild-type BRP signal peptide, specifically released $30 \%$ of the total amount of cloacin DF13 produced within $5 \mathrm{~h}$ after induction. Cells expressing the mBRP targeted by the unstable Lpp signal peptide did not release any cloacin DF13 (Luirink et al., 1991; Table 2).

Cells expressing the pJL44-encoded mBRP, targeted by the completely stable hybrid 9BRP11LppAla signal peptide, released $33 \%$ of the bacteriocin, comparable to the specific release by cells expressing the pJL22(SphI)encoded wild-type BRP (Table 2). This indicated that the 11 C-terminal amino acid residues of the BRP signal peptide, substituted here by residues from the Lpp signal peptide, are not directly involved in cloacin DF13-release.

Cells expressing the pJL47-encoded mBRP, targeted by the mutant 9BRPGlyAla10BRP signal peptide of intermediary stability, released $23 \%$ of the bacteriocin (Table 2). This indicated that substitution of the original residues of the BRP signal peptide (Phe ${ }^{-12}$ and $\mathrm{Ile}^{-11}$ ) by residues from the Lpp signal peptide $\left(\mathrm{Gly}^{-12}\right.$ and $\mathrm{Ala}^{-11}$ ) affected functioning of the BRP signal peptide in cloacin DF13-release.

Expression of the pJL42-encoded 10Lpp10BRP-BRP caused a net release of $20 \%$ (Table 2). This result is difficult to evaluate in view of the relatively low expression of the pJL42-encoded mBRP (Fig. 1a, lane 8; Fig. 1b, lane 7).

\section{Effects of mutant BRP-derived signal peptides on quasi-lysis and lethality}

The constructs encoding the mutant BRP-derived signal peptides (pJL45, pJL46, pJL49 and pJL43) allow us to investigate the effects of their expression on quasi-lysis 
and lethality in the absence of the mBRP, which itself has these effects (Luirink et al., 1991).

To investigate the effects on growth of expression of mutant signal peptides, cells were cultured in the presence and absence of IPTG, and the culture turbidity was monitored. In parallel, the growth of control cells harbouring PJL38 (encoding wild-type BRP signal peptide) or pJL40 (encoding wild-type Lpp signal peptide) was followed. Upon induction of the various mutant BRP-derived signal peptides, the cells exhibited lysis patterns of which the extent was decreased and/or of which the onset was delayed as compared with cells harbouring pJL38 (Table 2). Induction of the pJL40encoded unstable Lpp signal peptide, however did not affect cell growth at all (Table 2), indicating that all mutant BRP-derived signal peptides affected the growth of host cells.

To investigate the effects on cell viability, host cells expressing the mutant BRP-derived signal peptides were tested for their colony forming ability on broth agar plates as described in Methods. Control cells harbouring the expression vector pINIIIA1 or pJL40 (wild-type Lpp signal peptide) were not affected by any IPTG concentration used, whereas colony formation of cells harbouring PJL38 (wild-type BRP signal peptide) was sensitive to IPTG at a concentration of $125 \mu \mathrm{M}$ (Table 2). Cells expressing the mutant BRP-derivatives were sensitive to IPTG at levels between $63 \mu \mathrm{M}$ and $250 \mu \mathrm{M}$ (Table 2).

Apparently, expression of the mutant BRP-derived signal peptides is lethal to the host cells, but from these studies there is no clear correlation between the stability of a particular mutant BRP-derived signal peptide and its effect on the growth of host cells.

\section{DISCUSSION}

The aim of this study was to determine which part of the BRP signal peptide is responsible for stability, and to investigate a possible correlation between the stability of the BRP-targeting signal peptide and its functioning in cloacin DF13-release, quasi-lysis and lethality. Hybrid signal peptides were created, derived from the stable BRP signal peptide and the unstable Lpp signal peptide. In addition, a mutant BRP-derived signal peptide was constructed by substitution of two amino acid residues in the hydrophobic core region. The mutant signal peptides were expressed in the context of the preBRP or as a separate entity. Expression of the former constructs provoked the leakage of periplasmic proteins into the culture medium (data not shown), indicating correct targeting of the mBRP to the E. coli outer membrane (Van der Wal et al., 1992).

The cleaved-off 9BRP11LppAla signal peptide seems to be stable, indicating that the nine N-terminal residues of the BRP signal peptide, and/or the alanine residue, are important for signal peptide stability. Unexpectedly, the 9BRP12L $p$ signal peptide expressed alone, which had a C-terminal glycine residue, was not stable. Apparently, the C-terminal alanine residue, present in the cleaved-off 9BRP11LppAla signal peptide, is also important for stability. The reason for the instability of the 9BRP12L $p p$ signal peptide as compared to the 9BRP11LppAla signal peptide is not clear. Previously, we showed that the wildtype BRP signal peptide expressed alone is completely stable (see Fig. 1e) and accumulates in the cytoplasmic membrane (Van der Wal et al., 1992). An explanation might be that the 9BRP12Lpp signal peptide cannot properly insert into the cytoplasmic membrane and is degraded in the cytoplasm. Another explanation might be that the 9BRP12L $p p$ signal peptide inserts properly into the cytoplasmic membrane, but is sensitive to the signal peptide peptidases, in contrast to the 9BRP11LppAla signal peptide. The signal peptides derived from the colicin A, E2/E3 and cloacin DF13 BRPs having a Cterminal alanine residue are stable (Cavard et al., 1987; Pugsley \& Cole, 1987; Luirink et al., 1989), whereas the colicin E1 BRP signal peptide with a C-terminal glycine residue is unstable (Cavard, 1991), indicating that a Cterminal alanine residue is important for signal peptide stability. However, substitution of the C-terminal alanine residue of the colicin A BRP signal peptide by a glycine residue had little or no effect on signal peptide stability (S. P. Howard, personal communication), indicating that a C-terminal alanine residue is not the only prerequisite for signal peptide stability. This conclusion is supported by the observation that the 10LPD10BRP signal peptide (pJL42) and the mutant Lpp signal peptide (pJL32- $\mathrm{T}_{1}$ ), both having a $\mathrm{C}$-terminal alanine residue, are not stable.

The stable BRP signal peptide is extremely hydrophobic as compared to the unstable Lpp signal peptide and contains more bulky amino acid residues (Klein et al., 1988). It has been suggested that these characteristics are related to the stability of the BRP signal peptide (Luirink et al., 1991). To investigate this possibility, a mutant BRP signal peptide was constructed which contains two small less hydrophobic amino acid residues, including a residue known to destabilize $\alpha$-helices. The resulting mutant 9BRPGly Ala10BRP signal peptide is presumed to have a different secondary structure and a decreased hydrophobicity. These changes appeared to destabilize the BRP signal peptide, albeit not completely. In this respect, it is interesting to note that the hydrophobic core region of the unstable colicin E1 BRP signal peptide is not as long as those of the stable signal peptides of the colicin A, E2/E3 and cloacin DF13 BRPs. In addition, the hydrophobic core region of the unstable colicin E1 BRP signal peptide contains a residue capable of destabilizing $\alpha$ helices, in contrast to the stable BRP signal peptides (Klein et al., 1988). Taken together, these results indicate that there is a correlation between signal peptide stability and either the length of its hydrophobic core region or its secondary structure.

There seems to be a discrepancy between the observations that the 9BRP11LppAla signal peptide is as stable as the wild-type BRP signal peptide, whereas the 9BRPGly Ala10BRP signal peptide has an intermediary stability. The latter mutant signal peptide only differs from the wild-type BRP signal peptide at positions -12 
and -11 , whereas the 9BRP11L $p$ A Ala signal peptide contains, in addition, a stretch of nine residues derived from the Lpp signal peptide. Apparently, the additional Lpp signal peptide-derived residues compensate in an unknown way for the destabilizing effect of the glycine and alanine residues at positions -12 and -11 . In addition, since the stable $9 B R P 11 L p p A$ la signal peptide contains a short hydrophobic core region, it appears that the length of this region is not the only factor determining stability.

When the mutant 10Lpp10BRP signal peptide was expressed in the context of the slowly processed preBRP, it was not detected. However, the mutant 10Lpp10BRP signal peptide could be detected when it was expressed as a separate entity, but it was rapidly degraded, indicating that this signal peptide is unstable. Apparently, the $11 \mathrm{~N}$ terminal amino acid residues of the BRP signal peptide are important for signal peptide stability.

Taking these data together, it appears that both the $11 \mathrm{~N}$ terminal amino acid residues and the $\mathrm{C}$-terminal alanine residue of the BRP signal peptide together are important for its stability and that the length of the hydrophobic core region is not the only factor determining stability. However, the exact structural basis of signal peptide stability remains unknown.

When expressed as a separate entity, all BRP-derived signal peptides affected the growth and viability of the host cells, in contrast to the pJL40-encoded unstable Lpp signal peptide. The insertion of the more or less stable mutant signal peptides or their fragments into the cytoplasmic membrane might be responsible for the observed deleterious effects on growth and viability. Accumulation in the cytoplasmic membrane of the cleaved-off stable signal peptides of the colicin A- and cloacin DF13 BRPs, has been reported (Howard et al., 1991; Van der Wal et al., 1992). In addition, the latter signal peptide also accumulates in the cytoplasmic membrane when it is expressed as a separate entity (pJL38).

Previously obtained results suggested that the stable BRP signal peptide is involved in the release of cloacin DF13, since a BRP targeted by its own stable signal peptide mediated cloacin release, whereas a BRP targeted by the unstable Lpp signal peptide did not function in the release of cloacin DF13 (Luirink et al., 1991). In the present study, three mutant signal peptides targeting the BRP were tested with respect to cloacin release. The pJL44encoded stable mutant signal peptide was completely functional, whereas cloacin DF13-release by cells expressing BRPs targeted by the less stable (pJL42- and pJL47-encoded) mutant signal peptides was decreased. Although these observations indeed hint at a correlation between signal peptide stability and cloacin DF13-release, strong conclusions cannot be drawn, especially since expression of the pJL42-encoded BRP is relatively low, and secondly, the cleaved-off hybrid 10Lpp10BRP signal peptide was not detectable. We intend to generate a larger set of mutant signal peptides in a more random approach and test them for their capability to mediate cloacin DF13release.
When stability of the BRP signal peptide is required for efficient release of cloacin DF13, the peptide might directly cooperate with the mature BRP in the formation of a protein pore more or less specific for cloacin DF13. Future studies will be directed towards the putative poreforming abilities of the mature lipid-modified BRP and its stable signal peptide.

\section{ACKNOWLEDGEMENTS}

The investigations were supported by the Netherlands Foundation for Applied Sciences (STW) with financial aid from the Netherlands Organization for Scientific Research (NWO).

\section{REFERENCES}

Bergmeyer, H. U. \& Bernt, E. (1983). Determinations of metabolite concentrations with end point methods. In Methods of Enzymatic Analysis, pp. 163-181. Edited by H. U. Bergmeyer. Weinheim: Verlag Chemie.

Birnboim, H. C. \& Doly, J. (1979). A rapid alkaline extraction procedure for screening recombinant plasmid DNA. Nucleic Acids Res 7, 6727-6738.

Cavard, D. (1991). Synthesis and functioning of the colicin E1 lysis protein: comparison with the colicin A lysis protein. J Bacteriol 173, 191-196.

Cavard, D., Baty, D., Howard, S. P., Verhey, H. M. \& Lazdunski, C. (1987). Lipoprotein nature of the colicin A lysis protein: effect of amino acid substitutions at the site of modification and processing. J Bacteriol 169, 2187-2194.

De Graaf, F. K. \& Oudega, B. (1986). Production and release of cloacin DF13 and related colicins. Curr Top Microbiol Immunol 125, 183-205.

Dev, I. K., Harvey, R. J. \& Ray, P. H. (1985). Inhibition of prolipoprotein signal peptidase by globomycin. $J$ Biol Chem 260, 5891-5894.

Gennity, J. M., Kim, H. \& Inouye, M. (1992). Structural determinants in addition to the amino-terminal sorting sequence influence membrane localization of Escherichia coli lipoproteins. I Bacteriol 174, 2095-2101.

Howard, S. P., Cavard, D. \& Lazdunski, C. (1991). PhospholipaseA-independent damage caused by the colicin A lysis protein during its assembly into the inner and outer membranes of Escherichia coli. $J$ Gen Microbiol 137, 81-89.

Hussain, M., Ozawa, Y., Ichihara, S. \& Mizushima, S. (1982). Signal peptide digestion in Escherichia coli. Effect of protease inhibitors on hydrolysis of the cleaved signal peptide of the major outermembrane lipoprotein. Eur J Biochem 129, 223-239.

Joyce, C. M. \& Grindley, N. D. F. (1984). Method for determining whether a gene of Escherichia coli is essential: application to the $\operatorname{pol} A$ gene. J Bacteriol 158, 636-643.

Klein, P., Somorjai, R. L. \& Lau, P. C. H. (1988). Distinctive properties of signal sequences from bacterial lipoproteins. Protein Eng 2, 15-20.

Kunkel, T. A., Roberts, J. D. \& Zakour, R. A. (1987). Rapid and efficient site-specific mutagenesis without phenotypic selection. Methods Enzymol 154, 367-382.

Luirink, J., Van der Sande, C., Tommassen, J., Veltkamp, E., De Graaf, F. K. \& Oudega, B. (1986). Effects of divalent cations and of phospholipase A activity on excretion of cloacin DF13 and lysis of host cells. J Gen Microbiol 132, 825-834.

Luirink, J., De Graaf, F. K. \& Oudega, B. (1987). Uncoupling of 
synthesis and release of cloacin DF13 and its immunity protein by Escherichia coli. Mol \& Gen Genet 206, 126-132.

Luirink, J., Hayashi, S., Wu, H. C., Kater, M. M., De Graaf, F. K. \& Oudega, B. (1988). Effect of a mutation preventing lipid modification on the localization of the pCloDF13 encoded bacteriocin release protein (BRP) and on the release of cloacin DF13.J Bacteriol 170, 4153-4160.

Luirink, J., Clark, D. M., Ras, J., Verschoor, E. J., Stegehuis, F., De Graaf, F. K. \& Oudega, B. (1989). pCloDF13 encoded bacteriocin release proteins with shortened carboxyl-terminal segments are lipid modified and processed and function in release of cloacin DF13 and apparent host cell lysis. J Bacteriol 171, 2673-2679.

Luirink, J., Duim, B., De Gier, J. W. L. \& Oudega, B. (1991). Functioning of the stable signal peptide of the pCloDF13 encoded bacteriocin release protein. Mol Microbiol 5, 393-399.

Mandel, M. \& Higa, A. (1970). Calcium dependent bacteriophage DNA infection. $J$ Mol Biol 53, 159-162.

Masui, Y., Mizuno, T. \& Inouye, M. (1984). Novel high level expression cloning vehicles: $10^{4}$-fold amplification of Escherichia coli minor protein. Bio/Technology 2, 81-85.

Messing, J. (1983). New M13 vectors for cloning. Methods Enzymol 101, 20-78.

Miller, J. H. (1972). Experiments in Molecular Genetics. Cold Spring Harbor, NY: Cold Spring Harbor Laboratory.

Nakamura, K. \& Inouye, M. (1979). DNA sequence of the gene for the outer membrane lipoprotein of Escherichia coli: an extremely AT-rich promoter. Cell 18, 1109-1117.

Oudega, B., Ykema, A., Stegehuis, F. \& De Graaf, F. K. (1984). Detection and subcellular localization of mature protein $\mathrm{H}$, involved in excretion of cloacin DF13. FEMS Microbiol Lett 22, 101-108.

Pugsley, A. P. (1984). The ins and outs of colicins. I. Production and translocation across membranes. Microbiol Sci 1, 168-175.

Pugsley, A. P. \& Cole, S. T. (1987). An unmodified form of the ColE2 lysis protein, an envelope lipoprotein, retains reduced ability to promote colicin E2 release and lysis of producing cells. $J$ Gen Microbiol 133, 2411-2420.

Sambrook, J., Fritsch, E. F. \& Maniatis, T. (1989). Molecular Cloning: a Laboratory Manual, 2nd edn. Cold Spring Harbor, NY: Cold Spring Harbor Laboratory.

Sanger, F., Nicklen, S. \& Coulson, A. R. (1977). DNA sequencing with chain terminating inhibitors. Proc Natl Acad Sci USA 74, 5463-5467.

Schägger, H. \& Von Jagow, F. (1987). A tricine sodium-dodecylsulfate polyacrylamide gel electrophoresis for the separation of proteins in the range from 1 to $100 \mathrm{kDa}$. Anal Biochem 166, 368-379.

Tokunaga, H. \& Wu, H. C. (1984). Studies on the modification and processing of prolipoprotein in Escherichia coli. J Biol Chem 259, 6098-6104.

Van der Wal, F. J., Oudega, B., Kater, M. M., Ten Hagen-Jongman, C. M., De Graaf, F. K. \& Luirink, J. (1992). The stable BRP signal peptide causes lethality but is unable to provoke the translocation of cloacin DF13 across the cytoplasmic membrane of Escherichia coli. Mol Microbiol 6, 2309-2318.

Wu, H. C. \& Tokunaga, M. (1986). Biogenesis of lipoproteins in bacteria. Curr Top Microbiol Immunol 125, 127-157.

Received 1 June 1993; accepted 30 June 1993. 